\title{
Las reformas al código de trabajo en Francia: el Contrato de Primer Empleo (CPE) y el malestar social de la juventud
}

\author{
Armando Novoa García*
}

Fecha de recibido: marzo 28 de 2006. Fecha de aprobación: mayo 24 de 2006.

\section{RESUMEN}

En marzo del 2006 el parlamento francés aprobó la denominada "Ley por la igualdad de oportunidades", en ella se establecía un nuevo contrato de trabajo para los jóvenes o Contrato de Primer Empleo (CPE) que otorgaba prerrogativas a los empleadores en detrimento de las condiciones de trabajo de las personas entre los 16 y los 25 años. Esta ley fue rechazada por los estudiantes universitarios y por los sindicatos, que de forma inmediata iniciaron una serie de protestas en toda la república. El texto analiza la controvertida ley desde la evolución del derecho del trabajo en Francia y el proceso de globalización.

\section{PALABRAS CLAVE}

Reforma laboral, Código de Trabajo, Francia, Contrato de Primer Empleo.

\section{ABSTRACT}

In March of 2006 the French parliament approved the "law for equal opportunities", In it was established a new labor contract for young people or first job contract that granted prerogatives to employers in detriment of labor conditions of people between 16 and 25 years old. This law was rejected by the university students and by labor unions that immediately started a series of riots in al the republic. The article analyzes the controverted law from the labor right in France and the globalization process.

\section{KEY WORDS}

Labor reform, Labor Law, France, Contract of First Job.

Docente del Módulo Laboral de la Facultad de Derecho de la Universidad Santo Tomás, Bogotá. 
En mayo del 68 querían cambiar el mundo, hoy quieren que el mundo no cambie.

Michel Camdessus

Ex Director Fondo Monetario Internacional

Somos la generación sacrificada, no hay trabajo y encima, nos quieren ofrecer un contrato basura.

Un estudiante en las manifestaciones de París

El pasado 9 de marzo de 2006 el parlamento francés aprobó la denominada "Ley por la igualdad de oportunidades". El proyecto, que establece un nuevo contrato de trabajo para los jóvenes, o Contrato de Primer Empleo (CPE), fue presentado desde inicios de enero pasado por el Ministro del Empleo, Jean Louis Borloo, a iniciativa del primer ministro, Dominique de Villepín.

Una vez aprobada la propuesta, la reacción de los estudiantes y de las centrales sindicales francesas no se hizo esperar. Ese mismo día, decenas de miles de jóvenes salieron a las calles en cerca de 200 ciudades, y principalmente en París, para protestar contra lo que consideran una ley que instaura un modelo de contratación laboral para los jóvenes entre 16 y 25 años que precariza y deprime las condiciones en las cuales serán vinculados por los empleadores.

Más de cincuenta (50) universidades entraron en cese de actividades. Los medios de comunicación informaron que, a partir de esa fecha, se movilizaron más de un millón de manifestantes, entre jóvenes de liceos de secundaria, estudiantes de las universidades $y$ afiliados a las principales centrales sindicales francesas, como la C.G.T. y la C.F.D.T., que reclamaban la derogación de la ley.

La Universidad de La Sorbona, paradigma de la cultura francesa, fue ocupada por las fuerzas de policía y posteriormente cerrada ante las amenazas de una reacción violenta de los movimientos que protestaban contra la medida adoptada por el gobierno conservador de la UMP (Unión por un Movimiento Popular). Desde varios días antes la Escuela de Altos Estudios Sociales de París se encontraba ocupada por activistas, calificados por el gobierno como "anarquistas" y, el pasado 28 de marzo, en un hecho sin precedentes que algunos medios llamaron el "martes negro", se adelantaron varias movilizaciones en las cuales cerca de 3 millones de franceses protestaron contra la iniciativa gubernamental.

El $65 \%$ de los franceses encuestados por empresas de sondeos de opinión se manifestaron de acuerdo con las razones que esgrimen los estudiantes en contra de la ley. Entre tanto, la imagen favorable del Primer Ministro francés, Dominique de Villepin, descendió a menos del $40 \%$. Varios analistas y los medios de prensa consideran que estos episodios ponen en duda sus aspiraciones presidenciales en las elecciones que se realizarán en el primer semestre de 2007. Las disputas al interior del gobierno son cada vez más notorias. El Ministro del Interior, Nicolas Sarkosy, reclamó mayor disposición al diálogo con los estudiantes; incluso marcó claras diferencias con el primer ministro, al pronunciarse a favor de "la suspensión en la aplicación" de la ley.

El aspecto central de la protesta se dirigió contra un aparte de la "Loi pour l'egalité des chances", Ley por la Igualdad de Oportunidades, mediante el cual se incorpora al Código del Trabajo la figura 
del llamado "Contrat Premiére Embauche" (Contrato de Primer Empleo).

¿En qué consiste la Ley por la Igualdad de Oportunidades?, ¿cuál es el alcance de este Contrato de Primer Empleo, que ocasionó una reacción social de los jóvenes y trabajadores sin precedentes?, ¿servirán estas medidas legislativas para contrarrestar las altas tasas de desempleo juvenil existente en el país galo?, ¿pueden ser calificadas estas reformas como una radicalización de la ola neoliberal que se ha asentado en algunas de las naciones industrializadas?

Estos son algunos de los aspectos que se examinarán en el presente artículo.

\section{Los antecedentes: el malestar actual de la sociedad francesa}

El Contrato de Primer Empleo (CPE) hace parte de una serie de medidas anunciadas por el Primer Ministro Dominique de Villepin desde junio de 2005, cuando, en un discurso pronunciado ante la Asamblea Nacional francesa, esbozó las líneas generales de una nueva política para enfrentar las altas tasas de desempleo, especialmente en los sectores juveniles y entre los hijos de los inmigrantes. Con anterioridad a la expedición de la Ley por la Igualdad de Oportunidades la Asamblea francesa había adoptado, en agosto pasado, por iniciativa del gobierno, el denominado "Contrato de Nuevo Empleo" (CNE), que registra varias similitudes con el Contrato de Primer Empleo (CPE).

En la actualidad, Francia ostenta uno de los porcentajes de desocupación más altos de toda la comunidad europea, de $\mathbf{9 . 6 \%}$ del total de la población (que equivale a 4.5 millones de desempleados). El índice de desempleo juvenil está en la cifra del $22.3 \%$, por encima del promedio europeo del $\mathbf{1 8 . 5} \%^{1}$. Por otro lado, el fenómeno del desempleo juvenil en los países de la Unión llega a cifras muy superiores a la tasa promedio de la población adulta europea en condiciones de desempleo: España, el 19\%; Holanda, el $8 \%$, Gran Bretaña, el 7\%.

A la par con el desempleo juvenil, el mercado laboral del viejo continente, y en particular de Francia, muestra otro fenómeno que está incidiendo en las políticas y acciones de los gobiernos de Europa: la expansión de una nueva categoría de excluidos. Se trata de los "trabajadores pobres", fenómeno que cubre una franja bastante amplia de la población, y que tiende a ampliarse. Los trabajadores pobres aparecieron a finales de los años setenta, principalmente en los Estados Unidos, y hacen referencia a una situación laboral en la cual, a pesar de lograr la vinculación a un nuevo empleo, reciben unos ingresos que no les permiten una vida digna, ni el acceso a los beneficios básicos a que tendrían derecho como asalariados en condiciones normales de contratación laboral.

En la actualidad, según el Observatorio Francés de la Pobreza, existen en ese país alrededor de 1 millón de trabajadores pobres. En este índice se ubica a aquellos empleados que reciben un salario equivalente al $50 \%$ del promedio que recibe un trabajador sin familia ( 775 dólares mensuales, esto es, 387 dólares). En esas condiciones, un salario precario significa "una vivienda precaria, atención médica limitada y la entrada segura a los guetos de pobreza"2.

Además del creciente número de trabajadores precarios, se estima que Francia tiene alrededor de 3.7 millones de pobres. Esta cifra, aunque es

www.pag12.arg.com. "Non' a la flexibilización laboral, dicen los jóvenes”. 8 de Marzo de 2006.

www.lavozdegalicia.es. Ingrid Bazinet. 26 de marzo, 2006. 
menor de la que arrojan otros países como Estados Unidos (17\%) o Gran Bretaña (11\%), se hace más dramática debido a las altas tasas de desocupación, que rondan especialmente a los jóvenes y a los hijos de familias inmigrantes.

\section{Las revueltas del otoño de 2005: la exclusión del "subproletariado" de los inmigrantes}

Los síntomas del malestar social generado por realidades sociales como las anteriores se han expresado en distinta forma.

Una de ellos tuvo lugar en el mes de mayo de 2005, cuando el referéndum propuesto por el gobierno para la aprobación de la Constitución de la Unión Europea fue rechazado por la mayoría de los votantes que acudieron a las urnas. Entre las razones que en ese momento se invocaron, se mencionó como motivo principal el temor de que una vez aprobado el texto de la Constitución de la Unión, se impusieran las políticas de las corrientes más radicales del liberalismo económico y se desconocieran los avances sociales alcanzados en Francia ${ }^{3}$.

Pero, sin duda, el episodio más directamente relacionado con las protestas de marzo de 2006 se encuentra en los hechos ocurridos a finales del mes de octubre y a lo largo de noviembre de 2005, cuando se produjeron decenas de disturbios en los barrios periféricos de París y de otras ciudades. El punto de partida fue la reacción policial contra dos adolescentes que intentaron escapar a un control de las fuerzas de seguridad. El ataque ocasionó la muerte de los jóvenes.

El incidente dio origen a una respuesta inusitada de los jóvenes inmigrantes de los suburbios parisinos, que reaccionaron en forma violenta sobre miles de vehículos que resultaron quemados y destruidos. Decenas de escuelas, guarderías e instalaciones públicas fueron blanco de la protesta suburbana. Varios sectores de la sociedad francesa identificaron estas acciones incontroladas como la expresión de una nueva situación de inseguridad urbana que demandaba la adopción inmediata de medidas policivas y de mano dura por las autoridades gubernamentales. Algunos medios de comunicación indicaron que las protestas fueron la expresión de una "crisis de la civilidad urbana" y del "desarrollo de una sociedad paralela al margen de las leyes de la República" ${ }^{\prime 4}$.

El Ministro del Interior, Nicolás Sarkosy, calificó las protestas de los miles de jóvenes y adolescentes franceses de origen árabe y africano como una acción propia de "la escoria de los subur-

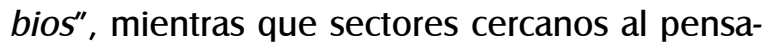
miento gubernamental consideraron que se trataba de nuevas "hordas de lobos" y de la expresión de un nuevo subproletariado poscolonial, muy lejano de los estudiantes de mayo de 1968, que en su momento hicieron propios los sueños de libertad e igualdad y se convirtieron en el símbolo emblemático de la utopía moderna.

El gobierno conservador enfrentó las protestas con medidas de seguridad, adoptadas con base en las facultades policivas que le otorga la Ley de Emergencia. El Ministro Sarkosy impuso el toque de queda en varios de los barrios parisinos en los cuales se produjo la protesta, entre ellos, en Clicy-sous-Boios, comuna habitada predominantemente por familias de inmigrantes. Como consecuencia, fueron detenidas cerca de 2.800 personas y otras 400 condenadas a prisión.

Durante el debate sobre el referéndum el tema de la globalización fue percibido como una amenaza contra la estabilidad en el empleo y como una forma de facilitar el traslado de industrias asentadas en Francia a otros países, para abaratar costos de producción. Auer, Peter. "Relocalización y pérdida de puestos de trabajo". En: www.ILO.

4 VIDAL, Dominique. "Acabar con el apartheid a la francesa”. Le Monde Diplomatique, Edición Colombia, diciembre de 2005. 
En los barrios afectados por los enfrentamientos y las acciones violentas de jóvenes anónimos habitan cerca de cinco millones de personas, la mayoría marginadas por la discriminación racial que afecta particularmente a los hijos franceses de los inmigrantes árabes y negros. Las tasas de desempleo existentes en los suburbios parisinos, para los jóvenes entre los 15 y los 24 años, son de cerca del $41 \%$. Esta situación ha generado efectos de todo tipo, no solo económicos, sino sociales y culturales, pues ha afectado las referencias vitales de los jóvenes de los sectores suburbanos. Laurent Bonelli, investigador de la Universidad de París $X$, señala que el malestar social generado por la situación social de subempleo, la marginalidad y los salarios precarios que predominan en el medio ha reintroducido "la incertidumbre respecto del futuro $y$, al impedir que los individuos hagan proyectos a largo plazo (inmobiliarios, matrimoniales, de diversión), los encierra en el presente y en una supervivencia cotidiana permeable a los desvíos"

Con los disturbios de octubre y noviembre de 2005 se hizo visible entonces una enorme "fractura territorial" en las ciudades, y la existencia de un "subproletariado", marginado de las ventajas culturales y del consumo que ofrecen los países industrializados.

Esta realidad, ha golpeado sobre todo a los hijos de los inmigrantes, muchos de los cuales, tras varios años de supervivencia en Francia -al igual que ocurre con los inmigrantes en otros países y ciudades europeas y en Estados Unidos- no conocen su idioma y en múltiples ocasiones son discriminados por el color de su piel, por sus tra- diciones culturales o, sencillamente, por la xenofobia rediviva originada en la creciente inmigración de quienes han abandonado sus paises huyendo de la pobreza, la falta de oportunidades o la violencia?

\section{La respuesta a la crisis social: la Ley por la Igualdad de Oportunidades}

Para dar respuesta a esta ola de pugnacidad urbana y a la situación de exclusión social descrita, el parlamento francés aprobó por iniciativa del gobierno la Ley por la Igualdad de Oportunidades.

En términos generales, esta reglamentación busca incentivar la creación de empresas en los barrios periféricos de las principales ciudades y facilitar la creación de empleo.

La Ley se expidió con base en las facultades que establece el artículo 49, aparte 3 de la Constitución francesa (cláusula especial de procedimiento), según el cual el gobierno puede poner en vigencia una norma sin la aprobación de la Asamblea Nacional ${ }^{8}$. En el trámite adelantado ante la Cámara de Diputados, el texto se aprobó por 329 votos (328 votos de los diputados del partido gobernante UMP y 1 de la UDF) contra 159 de los socialistas, comunistas y del Partido Verde.

La iniciativa no fue discutida con las centrales sindicales, ni hubo proceso alguno de consulta previa en torno a su contenido, a pesar de que ante los electores el primer ministro Villepin se había comprometido a no reformar el Código de Trabajo sin diálogo con los interlocutores sociales.

\footnotetext{
BONELLI, Laurent. "Estallido en los suburbios franceses". Le Monde Diplomatique, diciembre de 2005, Edición Colombia, p. 4.

Esta es la expresión que se utilizó en el Senado francés para establecer el objetivo del proyecto sometido a su consideración. Véase www.senat.fr. Migración laboral en el siglo XXI. De muchos ¿uno? En: www.ilo.org

El art. 49-3 de la Constitución dice: “El primer ministro podrá, previa discusión del Consejo de Ministros, plantear la responsabilidad del gobierno ante la Asamblea Nacional sobre la votación de un texto. En tal caso este texto se considerará aprobado, salvo si una moción de censura, presentada dentro de las 24 horas siguientes, fuere aprobada del modo establecido en el aparte anterior".
} 
El pasado 31 de marzo, el Presidente, Jacques Chirac, promulgó el texto de la ley, pero solicitó al primer ministro que se adelantara ante el parlamento un nuevo trámite con el objeto de introducir algunas modificaciones a los aspectos más polémicos de su texto.

Según Villepin, la Ley contempla cinco (5) objetivos centrales ${ }^{9}$ :

a) Favorecer la creación de empleo para los jóvenes de zonas urbanas "sensibles".

b) Reforzar la igualdad de oportunidades y la lucha contra la discriminación.

c) Ayudar a los padres de familia a ejercer en forma adecuada la patria potestad sobre sus hijos.

d) Reforzar el poder de las autoridades de policía para constatar la comisión de acciones delictivas y adelantar diligencias de transacción cuando se lleven a cabo actos de vandalismo e "incivilidad"10.

e) Crear un servicio civil voluntario.

En materia de empleo y de desarrollo económico, el primer ministro ha señalado que la Ley por la Igualdad de Oportunidades contiene varios instrumentos orientados a facilitar la creación de nuevos empleos para los jóvenes, para lo cual se contemplan, entre otras, las siguientes medidas:

a) Se establece la posibilidad para los empleadores de firmar contratos de trabajo denominados "Contrato de Primer Empleo", con el fin de estimular la vinculación laboral de jóvenes entre 16 y 26 años.

b) Con el propósito de "reducir la fractura social", se establece la posibilidad de crear "zonas francas urbanas", a partir del $1^{\circ}$ de agosto de 2006, en los barrios de más de $\mathbf{8 . 5 0 0}$ habitantes, "particularmente desfavorecidos", en las cuales los empresarios gozarán de un tratamiento tributario especial y más favorable. Estas zonas serán delimitadas mediante decreto gubernamental ${ }^{11}$.

c) Posibilita la formación profesional desde los 14 años, y la firma de un contrato de aprendizaje desde los 15, y estipula que las prácticas laborales en las empresas sean remuneradas cuando superen los tres meses.

d) Establece el contrato "de responsabilidad parental", según el cual, se pueden suspender o poner bajo tutela las ayudas recibidas a las familias cuando no exista respuesta de los jóvenes al ciclo educativo ${ }^{12}$.

Y, en lo que se refiere a la "igualdad de oportunidades" y a la "lucha contra la discriminación" ${ }^{13}$ se consagran varias medidas:

a) Se incluye en el Código de Acción Social la creación de una Agencia Nacional para la cohesión social y la igualdad de oportunidades, como un establecimiento público de carácter nacional, que contribuirá a realizar acciones en favor de las personas que experimenten dificultades para la inserción social o profesional. Esta agencia se orientará a la

www.premier-ministre.gouv.fr.

10 www.senat.fr, Artículo 27 del proyecto adoptado por el Senado el 5 de marzo de 2006.

1 Sección tercera de la Ley sobre "Zonas francas urbanas".

12 Artículo 24 del proyecto aprobado en el Senado.

13 Sección VI de la Ley adoptada en el Senado. 
atención de la población inmigrante residente en Francia.

b) Refuerza poderes de lucha contra la discriminación y por la igualdad (Halde).

Debe señalarse también que, con anterioridad a la expedición de la Ley, el gobierno había adoptado otras medidas, con el mismo objetivo de lograr mejores condiciones para la contratación laboral. Así, se expidió el llamado "Contrato de Nuevo Empleo" (CNE), orientado a desbloquear la contratación en pequeñas y medianas empresas de menos de 20 trabajadores; se anunciaron acciones de fortalecimiento de la Agencia Nacional para el Empleo (ANPE), que es en realidad una bolsa de empleo estatal, con el fin de garantizar la eficacia en la búsqueda de ocupación y la orientación adecuada para una formación profesional cualificada; se introdujeron reformas al régimen del aprendizaje y se adoptaron dispositivos para la flexibilización de la formación profesional. El Contrato de Nuevo Empleo, no tiene límites de edad, es indefinido, y se aplica exclusivamente a empresas de menos de 20 trabajadores.

Dominique de Villepin ha señalado que el propósito de la ley está dirigido a "reconstruir las condiciones de confianza en Francia, en particular, en el ámbito del empleo"; a limitar el desempleo, especialmente, el paro juvenil; y a aumentar la flexibilidad de las empresas, así como a crear mecanismos para mejorar la "cohesión social".

\section{El contenido del Contrato de Primer Empleo}

Ahora bien, en lo que se refiere al Contrat Premier Embauche (CPE), el primer ministro defiende su inclusión en el Código Laboral francés, pues con- sidera que se trata de "un verdadero contrato contra la precariedad" $\mathrm{y}$ de "una herramienta para combatir el paro entre los más jóvenes", que alcanza el $23 \%$ de la población juvenil, muy superior a la tasa de desocupación de $9.6 \%$ que afecta a la población en general ${ }^{14}$. Para Villepin, el Contrato de Primer Empleo es un contrato de "inserción", que busca lograr "un justo equilibrio entre la protección a los empleados y el dinamismo económico", teniendo en cuenta que "el empleo es también crecimiento (...) de las empresas" $^{15}$.

Esta nueva modalidad contractual, incluida en el Código de Trabajo, tiene las siguientes características $^{16}$ :

a) Se aplicará para la contratación de jóvenes entre 15 y 26 años y debe constar por escrito.

b) Este contrato no tiene duración definida. Se trata de un contrato de duración indeterminada en el cual, y en el lapso de los dos primeros años, la ruptura unilateral del mismo no genera las cargas económicas e indemnizatorias a cargo del empleador, como lo dispone el Código para los contratos a término indefinido.

c) Se establece que el Contrato de Primer Empleo se encuentra sometido a las disposiciones del Código de Trabajo, con excepción de los dos (2) primeros años, durante los cuales el empleador puede prescindir del empleado sin motivo o causa justificada. Existe pues, una diferencia sustancial entre este tipo de contratos y los contratos indefinidos, pues durante el período de los dos primeros (2) años el empleador puede terminar el contrato sin pago de indemnización alguna. En la

\footnotetext{
14 www.elmundo.es/mundodinero/2006/03/07.

15 www.premier-ministre.gouv.fr.

16 Sección Segunda de la ley, art. $8^{\circ}$. Empleo y formación.
} 
actualidad, el período de prueba que establece el Código de Trabajo francés para el contrato a término indefinido es de seis (6) meses, lo que significa que, en la práctica, este lapso de interinidad se aumenta en dieciocho (18) meses. Se establece entonces un período de prueba "alargado". En el contrato a término indefinido, una vez cumplido este período, el trabajador adquiere estabilidad plena.

d) Este lapso de dos años, durante el cual no existe ningún tipo de estabilidad, se denomina de "consolidación". Para el computo de este término, el empleador podrá tener en cuenta el tiempo que el empleado hubiera laborado en misión en otras empresas durante los dos años anteriores a la firma del contrato de primer empleo.

e) El contrato puede ser terminado por iniciativa del empleador o del asalariado, para lo cual la ruptura debe ser notificada previamente a la contraparte, con 15 días de anticipación, siempre que se hubiera trabajado por más de 6 meses. Si el contrato termina por iniciativa del empleador, debe pagar al asalariado, como indenmización, el equivalente del $\mathbf{8 \%}$ de los ingresos brutos recibidos hasta la fecha.

f) Este contrato da derecho al asalariado a acceder al beneficio de la formación profesional dentro de las condiciones que establece el Código de Trabajo, así como al reconocimiento de prestaciones de desempleo, algunas facilidades para alquilar vivienda y para acceder a créditos bancarios. A juicio del gobierno, este último aspecto permite que la reforma se inserte en la corriente de la denominada "flexsegurité" lo danés, en el cual se combinan fórmulas de mayor desregulación laboral con mejoras en la protección social y en las prestaciones para los desempleados.

g) La nueva modalidad contractual se dirige a las empresas de más de veinte trabajadores, pues para las empresas con menos de este número de trabajadores se estableció otro modelo de contratación, denominado "Contrato de Nuevo Empleo" (CNE). El Contrato de Nuevo Empleo también es considerado como una modalidad de contratación flexible.

h) Finalmente, el aparte IV del artículo $8^{\circ}$ de la ley indica que las condiciones y los efectos del Contrato de Primer Empleo deben ser objeto de una evaluación, a más tardar al 31 de diciembre de 2008, por una comisión conformada por representantes de los empleadores y de los sindicatos representativos.

\section{El debate sobre el alcance y Ios efectos del Contrato de Primer Empleo: inserción laboral para los jóvenes o contrato precario?}

El primer ministro ha señalado que este contrato es una buena vía de acceso directo hacia una vinculación laboral a término indefinido, pues se encuentra rodeado de garantías para el asalariado y facilita su formación profesional, en un contexto internacional en el cual es indispensable velar por la estabilidad y el crecimiento empresarial. Además, Villepin defiende este tipo de contratación con el argumento de que ofrece mayores ventajas a las establecidas para los contratos temporales o de duración definida, además de

"Flexseguridad" es un concepto que se ha venido adoptando en los países europeos. "La flexseguridad aparece como un nuevo término clave en el debate sobre el futuro de los mercados laborales europeos y en el desarrollo de políticas sociales. Se refiere al intento de compatibilizar altos niveles de flexibilidad laboral con altos niveles de seguridad". En www.barcelona.2004.org. Documentos. Flexeguridad. 
consagrar una vinculación de largo plazo, que permite la acumulación de experiencia y la inserción laboral de los jóvenes ${ }^{18}$.

Por el contrario, para los opositores a la iniciativa, que solicitaron el retiro de la ley, especialmente para las organizaciones estudiantiles de la juventud, como la Unión Nacional de Estudiantes Franceses (U.N.E.F.) ${ }^{19}$, y para las confederaciones sindicales más poderosas (la C.G.T. ${ }^{20}$ y la C.F.D.T.), Ios Contratos de Primer Empleo (CPE) y de Nuevo Empleo (CNE) institucionalizan una situación de precariedad laboral que deja sin opción de futuro a las nuevas generaciones y equivale a una "demolición" del Código de Trabajo. Se trata, dicen ellos, de un "Nuevo contrato precario para los jóvenes".

¿Cuáles son los argumentos que esgrimen las organizaciones juveniles y las agremiaciones sindicales?

En primer lugar, se indica que al establecer un período de prueba de dos (2) años, durante el cual el empleador puede terminar el contrato sin justificación alguna, se desconocen las garantías a favor de la estabilidad que rigen para los contratos de duración indefinida contenidas en el Código de Trabajo francés. Esta nueva modalidad contractual, dicen, abrirá las puertas para la generalización de un tipo de vinculación inestable y precaria.

En segundo lugar, creada una situación de esta naturaleza, durante el período de "consolidación" de dos años, que equivale a una especie de período de prueba prolongado, se producirá un vín- culo autoritario de obediencia incondicional que sustituirá las relaciones de compromiso y respeto que contempla el Código de Trabajo para los contratos de duración indefinida 0 , incluso, de duración determinada. Así, en los dos primeros años, la amenaza permanente del despido injustificado coartará toda posibilidad de reclamo de los derechos de los jóvenes vinculados mediante esta modalidad contractual.

En tercer lugar, aunque el Contrato de Primer Empleo no autoriza las prácticas empresariales ilegales contra sus empleados, en muchos casos podrá obligar a los trabajadores a laborar durante jornadas más extensas de las que declaran, pues dadas las altas tasas de desocupación, éstas se utilizarán como instrumento disuasivo para inhibir los reclamos de los asalariados ${ }^{21}$. En particular, se señala que bajo las nuevas condiciones el empleador aumentará de facto la programación de horas suplementarias de 180 a 220 horas por año; podrá incrementar subrepticiamente la jornada laboral a 48 horas semanales autorizada por la Unión Europea, desconocer las 35 horas alcanzadas durante los gobiernos socialistas, y abrirá la posibilidad de que se discuta la instauración de jornadas de hasta 65 horas (!!!) a la semana, con lo cual se establecería una flexibilización arbitraria y dictatorial del tiempo de trabajo ${ }^{22}$. Si eso Ilegara a ocurrir, la sociedad francesa se retrotraería a condiciones similares a las que regían en la década de los años 20, en el siglo pasado.

En cuarto lugar, existe el temor de que bajo esta modalidad contractual, los jóvenes entre 16 y 26 años permanecerán empleados, pero con interrupciones de dos en dos años, hasta llegar a los

\footnotetext{
18 www.premier-ministre.gouv.fr.

19 www.unef.fr.

$20 \quad$ www.cgt.fr.

21 THIBAULT, Bernard. Secretario General de la CGT: "Ce n'est pas le contrat du travail qui fait l'embauche". www.cgt.fr.

22 www.politis.fr/art 1184. BRUN, Therry. "Loi de cohesion sociales: la revolution conservatrice".
} 
10 años, en condiciones de precariedad ${ }^{23}$. Quienes alertan sobre esta eventualidad, señalan que en tales condiciones no habrá posibilidad de acceso a bienes y servicios básicos para alcanzar la independencia familiar y la autonomía personal ${ }^{24}$. El riesgo mayor se encuentra en el fraude a la contratación mediante el encadenamiento de sucesivos contratos en que se podrá terminar injustificadamente el vínculo laboral antes de que se cumpla, en cada lapso, el periodo de dos años. Incluso, se ha señalado que el tiempo de interinidad puede ser de hasta 12 años, pues bastará que un trabajador próximo a cumplir 26 años sea nuevamente enganchado, para que el contrato se extienda hasta la edad de los 28 años. Esta posibilidad permite proyectar que la nueva modalidad contractual cubrirá, adicionalmente, a cerca de 1.5 millones de jóvenes adultos. Además, en el texto de la ley no se contempla expresamente que el contrato se transforme automáticamente en contrato a término indefinido.

Los jóvenes consideran que "sin un trabajo consecuentemente remunerado y antigüedad laboral es imposible alquilar una casa. Los salarios son bajos, Ios trabajos inestables, los alquileres prohibitivos y las condiciones para alquilar un departamento son simplemente descabelladas. Alquilar 15 metros cuadrados en París cuesta entre 700 y 900 dólares por mes. Las agencias inmobiliarias exigen que los candidatos ganen cuatro veces el precio de alquiler, lo que es imposible para alguien de esa edad e incluso más"25. En tales circunstancias, un empleo inestable conduce a una situación de incertidumbre, de retardamiento de los proyectos de vida, a la "infantilización" de la vida cotidiana y a una permanente sensación de "transitoriedad", que impedirán crear vínculos estables frente al empleo y retardará la emancipación de su hogar familiar.

Los empresarios y el gobierno han señalado que, contrario a las críticas estudiantiles y de los sindicatos, se observará un comportamiento "ético" en el uso del Contrato (CPE), y en ningún caso se afectarán las garantías laborales. Incluso, los empleadores se han mostrado partidarios de la disminución del periodo de consolidación de dos a un año y de la justificación del motivo del despido.

En quinto lugar, la adopción del Contrato de Primer Empleo conducirá a la supresión de la figura de los licenciamientos o despidos colectivos por razones económicas, contenida en el Código de Trabajo, que están sujetos a rígidos trámites de control por las autoridades laborales. En efecto, al establecerse un contrato de duración indeterminada, que no indefinido, durante los dos primeros años, se reemplazarán de hecho los licenciamientos colectivos por licenciamientos por motivos personales. Quienes así opinan señalan que tanto el Contrato de Primer Empleo como el Contrato de Nuevo Empleo permiten una modalidad de retiros "indoloros" para el cuerpo social, que anula la acción colectiva y genera un desequilibrio de fuerzas entre el status de protección colectiva que representan los sindicatos y los nuevos poderes empresariales que precarizan e individualizan las relaciones laborales ${ }^{26}$. Se trata,

\footnotetext{
${ }_{23}$ “Ayer, hasta los profesores y los padres se sumaron a las marchas porque, como decía André Valain, un profesor universitario de 56 años "al ritmo actual, mis alumnos no tendrán ni una casa segura ni un trabajo digno. Dudo mucho que las empresas jueguen el juego de la honestidad. Lo más seguro es que contraten a los jóvenes durante dos años y luego, a la hora de extender el contrato, los despidan para tomar otro joven y así pagar las cotizaciones sociales correspondientes". En www.pag12.arg.com. 8 de marzo de 2006.

24 Esta situación ha sido descrita coloquialmente así: el dilema del Contrato de Primer Empleo es aceptar el contrato "basura" o depender indefinidamente del papá. Tal vez esta situación explica porqué los padres de familia también se han vinculado a las movilizaciones de protesta.

$25 \quad$ www.pag12.com.arg, 8 de marzo de 2006.

26 SARIDAN, Patrick. "Contrat Premiére Embauche (CPE): una précarisation por le droit". www.inegalités.fr.
} 
en últimas, de una reforma que hace parte de una tendencia más general hacia la individualización y el aislamiento en la vida cotidiana de los empleados, que anula las expresiones y la acción colectiva en el lugar de trabajo.

También se señala que este tipo de contratos tiene como verdadero propósito facilitar la adaptación de las empresas y de los mercados a las fluctuaciones del ciclo económico y a la gestión eficiente de la producción, sobre la base de bajos salarios. Se trata de una vía diferente a la que parecen escoger las autoridades alemanas y la primera ministra de ese país, que han presentado una iniciativa para flexibilizar los licenciamientos colectivos por razones económicas.

$Y$, en sexto lugar, aunque el gobierno indica que el Contrato de Primer Empleo, así como el Contrato de Nuevo Empleo, servirán para superar los problemas de rigidez que representa para las empresas el Contrato de Duración Indefinida (CDI), en el fondo, dicen los opositores, estas modalidades de contratación laboral conducirán a la expansión, ya no por fuera, sino dentro de la legalidad, de contratos mal remunerados, con horarios flexibles y sin ningún tipo de estabilidad, no sólo para los jóvenes sino para todos los trabajadores franceses. Es decir, conducirán a la legalización de la precariedad en el empleo.

Además de todo lo anterior, las confederaciones sindicales señalan que a esta situación debe agregarse que la Ley por la Igualdad de Oportunidades establece otra figura: la modalidad de los trabajos "voluntarios", que, dada la situación de desocupación masiva, permitiá disfrazar formas atípicas y precarizadas de vínculos laborales, como si se tratara de un servicio "social" de mera liberalidad.
En fin, para las agremiaciones estudiantiles, para los sindicatos y para buena parte del propio pensamiento académico francés, la Ley por la Igualdad de Oportunidades y el Contrato de Primer Empleo son un paso más en una estrategia orientada a "demoler el Código del Trabajo", con el argumento no demostrado de que la flexibilidad laboral aprobada generará más y mejores puestos de trabajo para la juventud.

De esta forma, aunque el contrato de duración indefinida no desaparece del Código, su aplicación estará sujeta a condiciones tales de flexibilidad y a nuevas formas precarias de contratación, que será desplazado de las relaciones de trabajo.

\section{El significado actual del "inmovilismo" social}

Entre tanto, el debate sobre las reformas laborales necesarias para enfrentar el desempleo entre los jóvenes continúa. Las partes no ceden en sus posiciones y la espiral de la protesta callejera continua en ascenso.

El primer ministro, Dominique de Villepin, acusa de "inmovilismo" a los sectores que se oponen a la reforma. Algunos diarios europeos califican a la juventud francesa como extremadamente resistente a las nuevas tendencias de la economía mundial. Las movilizaciones estudiantiles, dicen, son la expresión una "revolución conservadora" a favor del statu quo, que se muestra refractario a cualquier cambio para enfrentar la situación de crisis social y los retos de la globalización ${ }^{27}$. El gobierno se defiende de las críticas contra el Contrato de Primer Empleo, señalando que en la actualidad "el $70 \%$ de los contratos son de duración definida y la mayoría de ellos no dura más

\footnotetext{
27 El ex director del Fondo Monetario Internacional, Michel Camdessus, señala que las acciones estudiantiles son la expresión del enorme "conservadurismo de clases y sectores tradicionalmente progresistas. En mayo del 68 , querían cambiar el mundo, hoy quieren que el mundo no cambie".
} 
de 1 mes", y que lo que se pretende es, precisamente, evitar la multiplicidad de contratos de duración limitada, "para ayudar a la inserción de la juventud en el mercado de trabajo"28.

Villepin ha señalado que el ordenamiento jurídico impide que la ley sea retirada o suspendida, pero abrió las puertas para cambios que no "desnaturalicen" el sentido de la reforma. Los jóvenes reclaman que se derogue pues su aplicación conducirá a una mano de obra barata, no aumentará los puestos de trabajo e incrementará los beneficios de los empleadores que se verán liberados de pagar las cargas sociales de un contrato de duración indefinida.

El 31 de marzo el presidente Chirac anunció la promulgación de la ley pero solicitó que, de manera inmediata, fuera modificada en dos aspectos: la reducción del período de consolidación de 2 a 1 año y la inclusión de la justificación del despido que se produzca durante este lapso. El pronunciamiento del presidente francés supone, de hecho, la devolución de la ley al parlamento para su reconsideración. Esto equivale a sancionar la ley para no aplicarla. Los analistas señalan que se trata de una maniobra para desarmar a sus adversarios y para aliviar las disputas entre los ministros Villepin y Sarkosy ${ }^{29}$.

El gobierno y los empresarios simpatizan con la idea de un vínculo laboral similar al anglosajón, en el que no existen las limitaciones que caracterizan el código francés que favorece la estabilidad.
Entre las opciones para superar la controversia que ha generado la expedición de la Ley por la Igualdad de Oportunidades se mencionan la posibilidad de reducir el período de consolidación y de justificar las razones del despido, tal como lo anunció el presidente Chirac y lo habían propuesto los empresarios. También, se menciona la extensión del contrato de aprendizaje o la adopción de un modelo de contrato único más flexible ${ }^{30}$. Los estudiantes insisten en que la Ley debe ser derogada.

Sin duda, se trata de una confrontación de grandes dimensiones, que tiene alcances más allá del debate sobre el aspecto puntual del Contrato de Primer Empleo. La juventud francesa rechaza este modelo social al cual califican de precario y consideran estas nuevas modalidades de vinculación laboral como contratos "basura" y "desechables $^{\prime \prime 31}$, que equivalen a una condena indefinida al ostracismo social, sin ningún futuro estable.

\section{La decisión del Consejo Constitucional y el Convenio 158 de la Organización Internacional del Trabajo ${ }^{32}$}

Los opositores a la reforma laboral aprobada impugnaron ante el Consejo Constitucional francés varios apartes de la Ley por la Igualdad de Oportunidades. Entre los aspectos atacados se encuentra el relativo al Contrato de Primer Empleo (art. $\left.8^{\circ}\right)$. La impugnación se orientó a cotejar el contenido de la ley con el principio de igualdad en el trato, el derecho al empleo, el derecho de de-

\footnotetext{
28 www.premier-ministre.gouv.fr.

29 COLOMBANI, Jean-Marie. "Louvoiement", 31 de marzo. www.lemonde.fr.

30 Así lo recomendó una comisón encabezada por el ex director del Fondo Monetario Internacional, Michel Camdessus.

31 El concepto de contrato "basura" apareció a mediados de los 90 en Europa. "Son contratos temporales a muy corto plazo, que permiten remuneraciones inferiores al salario mínimo, que no son para la formación, que restringen las prestaciones sociales (la contingencia, por ejemplo, del desempleo) y que contemplan exenciones en la cuota empresarial a la Seguridad Social. En suma, estos contratos permiten todo tipo de abusos, al tiempo que inciden en una devaluación social del trabajo". MONTES, Pedro. El desorden neoliberal. Trotta, 1996, p. 82.

32 www.conseil-constitucionnel.fr.
} 
fensa, la prevalencia del Convenio 158 de la Organización Internacional del Trabajo relativa a los principios que deben regir la terminación del contrato de trabajo, y las normas laborales contenidas en la Carta Social Europea. Igualmente, la ley fue atacada por la forma como se llevó a cabo el trámite para su aprobación y las atribuciones que invocó el gobierno para evitar la última votación en el parlamento. En particular, se resaltó el hecho de que no existe motivo para la diferencia en el trato entre dos asalariados que están en situación idéntica, uno vinculado con contrato a término indefinido y otro bajo las reglas del CPE.

El Convenio 158 de 1982 de la OIT, "sobre la terminación de la relación de trabajo por iniciativa del empleador"33, establece un principio general de estabilidad en el empleo, de manera que "no se pondrá término a la relación de trabajo de un trabajador a menos que exista para ello una causa justificada relacionada con su capacidad o su conducta o basada en las necesidades de funcionamiento de la empresa, establecimiento o servicio".

El Convenio establece que no se podrá terminar una relación de trabajo sin que se haya adelantado un procedimiento previo, con observancia del derecho de defensa (Sección B, art. $7^{\circ}$ ). Igualmente, contempla el derecho a recurrir el despido, cuando considere injustificada la terminación, ante un órgano judicial o un tribunal independiente. También, establece el deber de consulta previa con los representantes de los trabajadores poniendo en su conocimiento los motivos o causas de esta determinación.

Al examinar los cargos, el Consejo Constitucional consideró que el artículo $8^{\circ}$, relativo al Contrato de Primer Empleo, se tramitó adecuadamente y no se configuró ningún vicio de procedimiento. Además, consideró que el término de 2 años, o período de consolidación, en el cual el empleador puede dar por terminado el contrato sin causa justificada, no es incompatible con el Convenio 158, como tampoco lo es el hecho de que se libere al empresario del pago regular de una indemnización, a pesar de que en los ataques judiciales presentados se llamó la atención sobre el hecho de que dos trabajadores en la misma condición podrían ser tratados de manera diferente y, para uno de ellos, discriminatoria, por el solo hecho de la edad.

El Consejo Constitucional concluyó que el nuevo contrato tiene como finalidad facilitar la inserción profesional, especialmente de los jóvenes con baja calificación profesional, lo que justifica el trato diferente. De la misma forma, invocó la primacía del principio del interés general para respaldar el modelo contractual adoptado por el parlamento francés. Así mismo, y en relación con este aspecto, el Consejo Constitucional recordó que sus competencias son de una naturaleza diferente a las que posee el órgano legislativo, por lo que no le compete hacer consideraciones de naturaleza diferente a la estrictamente constitucional.

Sobre el cargo relativo a la violación del derecho de defensa, el tribunal constitucional concluyó que los principios del debido proceso y el derecho de defensa se aplican cuando existe un motivo disciplinario, pero no cuando se está ante otras causas diferentes de licenciamiento, como ocurre en el evento del Contrato de Primer Empleo. Además, y para finalizar, señaló que el asalariado puede recurrir ante los tribunales ordinarios para que estos determinen si se debió invocar una causa o no para el despido.

33 Aparte relativo a Normas y principios y derechos fundamentales de trabajo. www.ilo.org. 
De mayo de 1968 a marzo de 2006: de la generación de la utopía a la generación "sacrificada"

Muchos recuerdan ahora la situación de 1994, cuando el primer ministro francés Eduard Balladur se vio forzado a renunciar a su cargo por la presión de la movilización desatada contra la idea de instaurar un contrato laboral que reducía el salario mínimo de los jóvenes. Otros más, se duelen de la falta de "grandeza" de la protesta estudiantil y no dudan en señalarla como la demostración de la "decadencia" a que ha llegado la nación francesa y de la "disfuncionalidad" institucional que hace imposible las reformas ${ }^{34}$.

Tampoco han faltado las comparaciones con mayo de 1968. Daniel Cohn-Bendit, el emblemático líder de esa época ha dicho que se trata de fenónemos distintos: "Las motivaciones son distintas. La crisis de ese entonces era moral, política. Hoy se trata de una crisis social, con jóvenes que se encuentran frente al desempleo de masa y tienen miedo".

La diferencia central se encuentra en los contextos de una y otra situación. Mayo del 68 fue la expresión cultural de la rebeldía estudiantil en un momento de fortaleza del Estado del bienestar. Hoy, la movilización social tiene otro origen. Con la globalización y las fórmulas de libertad económica, los términos de la lucha política se han invertido. Mientras los estudiantes y los sindicatos pretenden conservar los derechos laborales alcanzados en la segunda mitad del siglo XX, el gobierno y los empresarios apuestan a una economía competitiva en un mundo integrado por los mercados. Existe en la actualidad una revisión radical del modelo de relaciones laborales hereda- do de las etapas anteriores del capitalismo desarrollado.

Los mismos estudiantes se autocalifican como una "generación sacrificada", que se enfrenta a la escasez de trabajo y a la inseguridad laboral. Es la falta de esperanza lo que más les preocupa.

Desde una perspectiva más general, el debate que se adelanta en Francia hace parte de una situación global en la cual concurren varios aspectos: la mundialización de las relaciones económicas, el cambio tecnológico, la flexibilidad del mercado de trabajo, las altas tasas de desempleo entre los jóvenes, la proliferación de modalidades de contratación que se encuentran por debajo de los estándares de las legislaciones nacionales, los procesos de relocalización mundial y de expatriación de la producción que presionan por el establecimiento de nuevas condiciones laborales que faciliten un incremento en la rentabilidad de las empresas.

La sociedad francesa se enfrenta entonces a una crisis de primer orden que tiene a la juventud como actor principal y al contrato de trabajo como el objeto de una disputa de profunda significación.

Tal vez, valga recordar alguna de las reflexiones de Eric Hobsbawm, el gran historiador inglés del siglo $X X$, que se preguntaba sobre la despolitización de los jóvenes y respondía que no era claro su papel a inicios de esta centuria ${ }^{35}$. Las movilizaciones que han convulsionado el corazón de Europa parecen indicar que sus vaticinios deben ser nuevamente examinados. La juventud está reaccionando a los efectos de una situación global que presiona hacia el desmejoramiento

DESPONDS, Didier. En www.yahoo.com. Fin de regne ou (et) fin de régime?

35 HOBSBAWM, Eric. "Entrevista sobre el siglo XXr". Crítica, p. 133. 
en las condiciones de empleo y que los condena a un mundo sin ilusiones ${ }^{36}$.

\section{La Organización Internacional del Trabajo, el empleo de los jóvenes y el trabajo decente}

En el mundo, las tasas de desempleo para los jóvenes son mayores que las de la población adulta. Según la Organización Internacional del Trabajo, la gran mayoría de los puestos disponibles para los jóvenes están mal remunerados, y no ofrecen perspectivas de progreso ni de una verdadera inserción social. La mitad del desempleo mundial afecta a los jóvenes entre 15 y 24 años y según el Director de la O.I.T., aquellos tienen tres veces más posibilidades que los adultos de quedarse sin empleo ${ }^{37}$. En el sector informal se ubica el $93 \%$ de los puestos de trabajo para los jóvenes. Sus salarios son $44 \%$ más bajos que en la economía formal y la protección social y los beneficios propios de una vinculación estable son prácticamente inexistentes.

El problema del desempleo juvenil ha sido motivo de examen por la Organización Internacional del Trabajo desde años atrás. Particularmente, este tema se examinó a partir de la $86^{\circ}$ reunión de la conferencia celebrada en Ginebra, en junio de 1998. Allí se consideró que el asunto plantea problemas fundamentales para el mundo del trabajo.

En términos generales, la OIT ha considerado que programas puntuales orientados a atacar el desempleo juvenil en condiciones de inestabilidad, bajos salarios y pocas opciones de promoción profesional, han sido experiencias poco eficaces para disminuir el paro. El desempleo juvenil no "obedece a una deficiencia intrínseca de los trabajadores jóvenes" ${ }^{38}$, pues el problema se ubica realmente en la escasez del empleo y en la falta de articulación de la educación secundaria y universitaria a los requerimientos económicos y a los procesos productivos.

Más recientemente, la OIT ha llamado la atención sobre el hecho de que a pesar del crecimiento económico que se registró a lo largo de 2005, esta situación no logró contrarrestar el número global de personas en busca de trabajo, en especial de los jóvenes sin empleo. "Estamos enfrentando una crisis mundial del trabajo de enormes proporciones", señaló su Director General Juan Somalia.

En la conferencia internacional adelantada sobre el tema de desempleo juvenil ${ }^{39}$ en el 2005 se presentó un informe en el que se señala que conceptos como el de transición, para diseñar políticas de integración de los jóvenes al mercado de trabajo, resultan insuficientes para comprender y atacar el problema:

La primera y más real solución se encuentra en un aumento importante de la demanda agregada en la mayoría de los países, mediante la reforma de las políticas internacionales, con el objeto de brindar más espacio político y un mayor apoyo internacional a los países en desarrollo, así como una mayor flexibilidad nacional en sus políticas fiscales y monetarias. Estas reformas eran necesarias para crear vías de accesos a un trabajo decente para los jóvenes pero resultan insuficientes sin una combinación adecuada de políticas micro y meso económicas, incluidas tanto las

\footnotetext{
36 El filósofo y sociólogo alemán Alex Hanneth llama la atención sobre el hecho de que los elevados niveles de movilización social en Francia parecen marcar un punto de ruptura con el "vasto proceso de despolitización y de privatización de la existencia" que se han impuesto en los últimos años. Para él, se ha despertado "la conciencia de que las cosas pueden cambiar" $y$ de que el trabajador debe ser valorado como un sujeto de derechos y no solo como una variable de los costos de producción. Véase: www.lemonde.fr. 1 de abril 2006.

37 www.ilo.org. Véase: comunicados de prensa 2006.

38 NOVOA GARCÍA, Armando. “Empleo, desempleo y reforma laboral”. En: Actualidad Laboral y Seguridad Social, № 94, Legis, julio-agosto de 1999.

39 Conferencia Internacional del Trabajo, 93 reunión, Ginebra, junio de 2005. Comisión del empleo de los jóvenes. www.ilo.org.
} 
políticas activas del mercado de trabajo como las políticas industriales y salariales, y lo que es más importante, lograr un compromiso de trabajo renovado con la impartición de educación gratuita para todos. Igualmente se señaló que era necesario adoptar medidas para evitar que los jóvenes se quedaran encasillados en empleos precarios y mar remunerados, bajo la promesa de contratos de transición que no representaban ningún buen futuro para los jóvenes ${ }^{40}$.

Y, en la "Reunión tripartita sobre el empleo de Ios jóvenes: el camino a seguir", la OIT señaló el reto: cómo alcanzar empleo digno para los jóvenes, $y$ a través de qué reformas ${ }^{41}$.

\section{Las reformas laborales en Francia y la realidad colombiana}

Las protestas adelantadas en Francia indican que el camino tomado por las autoridades gubernamentales no cuenta con el consenso social básico necesario para la puesta en marcha de la reforma al Código Laboral. Ahora será necesario replantear sus contenidos. Las movilizaciones han demostrado que cualquier cambio deberá ser concertado con los interlocutores de la producción y con los gremios estudiantiles.

¿Qué enseñanzas podemos extraer en nuestro medio sobre el debate que se adelanta en Francia?

La Ley 789 de 2002 introdujo una serie de modificaciones al Código Sustantivo de Trabajo con la promesa de la generación de empleo. Esta reforma se aprobó, al igual que en Francia, sin la concertación y el diálogo social que establece el Art. 56 de la Constitución Política. Los argumentos, en uno y otro caso, han sido similares. Su pretensión fue la de facilitar la creación de empleo y mejorar las condiciones de competitividad laboral. Para el efecto, se adoptaron nuevos con- ceptos como el del "sistema de protección social", "orientado a crear las condiciones para que los trabajadores puedan asumir las nuevas formas de trabajo, organización y jornada laboral y simultáneamente se socialicen los riesgos que implican los cambios económicos y sociales" (Art. $\left.1^{\circ}\right) . Y$, al igual que en ese país, en la Ley 789 se estableció la conformación de una comisión mixta para evaluar su impacto.

La reforma introdujo varios cambios al Código Sustantivo de Trabajo, como el muy controvertido de la fijación de nuevos períodos de trabajo ordinario y nocturno, y la reducción de la jornada nocturna solo entre las 10 p.m. y las 6 a.m. Con ello, se disminuyó el período para el reconocimiento por el empleador de los recargos del 35\% entre las 6 p.m. y las 10 p.m. Así mismo, flexibilizó las condiciones para el despido, al reducir los montos de las indemnizaciones.

Igualmente, se expidió una nueva reglamentación para la "relación de aprendizaje" (art. 30 de la Ley), según la cual los pagos que recibe el aprendiz -concepto que se suprime de la leyson "un apoyo de sostenimiento mensual, el cual en ningún caso constituye salario". Tal remuneración es inferior al salario mínimo legal en una proporción diferente, según se trate de la fase "lectiva" (50\%) o de la "fase práctica" (75\%). En ningún caso esta remuneración deslaboralizada podrá ser objeto de convenios o contratos colectivos o de laudos arbitrales derivados de la negociación colectiva. Sin duda, la reforma se orientó a sustraer la relación laboral de los aprendices de las normas propias del mundo del trabajo.

La ley 789 estableció también mecanismos de "protección social" para el desempleo, pero estos no han producido los efectos esperados. Aho-

\begin{tabular}{ll}
\hline $40 \quad$ Ibíd. \\
$41 \quad$ Ibíd.
\end{tabular} 
ra, se plantea disminuir aún más los costos laborales, sin evaluar si el camino de reducir salarios y precarizar el empleo es la vía correcta para generar nuevos puestos de trabajo ${ }^{42}$; y si los efectos que una solución de este tipo produce sobre los ingresos de los trabajadores están en concordancia con el concepto de empleo digno que defiende la OIT.

Aun no se han realizado los balances sobre sus efectos, como la propia Ley lo estableció. La reforma afectó los ingresos de los trabajadores, flexibilizó algunos elementos del contrato de trabajo y facilitó las condiciones para el despido, pero no ha mejorado la protección a los desempleados o a quienes han perdido sus puestos de trabajo. Estamos lejos del concepto de flexseguridad que toma fuerza en Europa, como se reseñó atrás.

Tal vez, y por estas circunstancias, varios sectores reclaman ahora la derogación de la Ley 789 de 2002.

¿Ha caído realmente la tasa de desempleo entre los jóvenes?, ¿existen hoy, como consecuencia de la Ley 789, mejores condiciones de empleo para los jóvenes? Y, ilos empleos creados, están rodeados de garantías básicas que permitan hablar de empleos decentes?, ilas reformas al contrato de aprendizaje han permitido una mejor preparación profesional de los jóvenes enganchados bajo las nuevas condiciones?

Estas son preguntas pertinentes en Colombia, a propósito de las grandes convulsiones sociales que ocurren en Francia.

La fuente ideológica de los cambios que hoy se controvierten en ese país es similar a la que inspiró las reformas que se han adelantado en nuestro medio en los últimos 15 años.

Lo que hace la diferencia entre una y otra realidad, entre uno y otro país, además de los niveles de desarrollo económico y bienestar social que no son comparables, es la reacción de los sectores afectados por estas transformaciones.

En el caso de Francia, las protestas se dirigen a defender los derechos sociales alcanzados en el Estado de bienestar. Y, en Colombia, ¿cuándo tendremos un debate de esta naturaleza, para hacer realidad el Estado social de derecho que consagra la Constitución?

42 En: Reforma laboral: ¿Falta gestión y resultados? Actualidad Laboral y Seguridad Social, Legis, enero-febrero de 2006. 